\title{
DEVELOPMENT OF AN ANALYTICAL DYNAMIC MODEL OF A VIBRO-COMPACTOR USED IN CARBON ANODE PRODUCTION
}

\author{
Fatma Rebaïne$^{1}$, Mohamed Bouazara ${ }^{1}$, Daniel Marceau ${ }^{1}$, Duygu Kocaefe ${ }^{1}$, Brigitte Morais $^{2}$ \\ ${ }^{1}$ Centre universitaire de recherche sur l'aluminium (CURAL), Université du Québec à Chicoutimi, 555, Boul. de l’Université, Chicoutimi, \\ Québec, Canada, G7H 2B1 \\ ${ }^{2}$ Aluminerie Alouette inc., 400, Pointe-Noire Road, C.P. 1650, Sept-Îles, Québec, Canada, G4R 5M9
}

Keywords: vibro-compactor, dynamic, anode, frequency

\begin{abstract}
The carbon anode quality has a significant impact on the production of primary aluminum. Their performance can be evaluated by their various mechanical, electrical, physical, and chemical, properties such as density, electric resistivity, $\mathrm{CO}_{2}$ and air reactivities. The focus of this work is to study the various parameters of the vibro-compaction, which is one of the critical steps in the process of anode manufacturing. In this work, a dynamic model of a vibro-compactor is developed. The vibrocompactor is modeled as a rigid mass suspended on springs and dampers and subjected to harmonic external excitation. This model is used to identify the optimal conditions of the vibrocompacting process. These conditions are obtained through a correlation between the analytical vibro-compaction parameters and data from an industrial vibro-compactor. The use of optimum parameters will help improve the anode performance and, consequently, lead to better productivity and reduction on environmental impact.
\end{abstract}

\section{Introduction}

The aluminum industries in Quebec consumes alone about 1.27 million tons per year of carbon for anode production. The quality of anodes is widely influenced by the quality of raw materials and the manufacturing process. Before 1980, the hydraulic presses were used for the fabrication of anodes but now most of the presses have been replaced by the vibro-compactors due to their greater efficiency $[1,2]$. However, the control of the various parameters of vibro-compaction is quite relevant because the vibro-compactors require much more efficient control and maintenance. During the manufacturing process, the raw materials coke, recycled anodes, butts) are crushed, mixed with pitch and used for forming the paste. After that, they are placed in a vibrocompactor for shaping followed by baking and cooling. The efficiency of each of the manufacturing steps is important to improve the quality and mechanical properties of the anodes. Vibro-compaction is one of the most critical steps during the fabrication of anodes. If anodes are not well vibrated, their mechanical strength decreases and in turn this causes the premature crack formation. Proper vibration can be achieved by using the optimum values of time, frequency level, load and ensuring a uniform vibration inside the mould.

\section{Vibro-compactor}

The vibro-compactor consists mainly of a vibrating table supported on shock absorbers (vibration isolators), a mould where the anode paste is poured and a follower weight having a loading system which helps to compact the anode paste. Below the vibrating table, there is a rotating motor with eccentric weights that can create a rotation unbalance with a certain excitation frequency thus allowing the system to vibrate. Figure 1 shows a schematic of the key components of vibro-compactor.

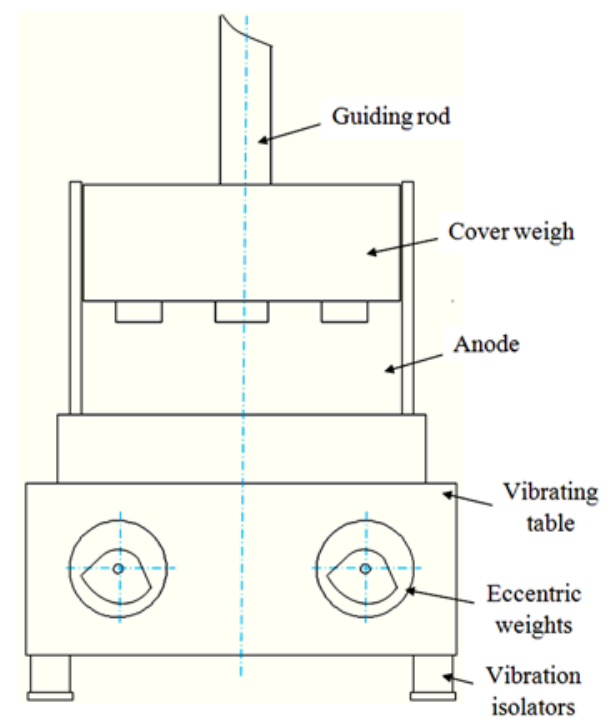

Figure 1: Schematic drawing of the vibro-compactor.

Some vibro-compactors also include a vacuum, to have a better efficiency. With the use of vacuum, the apparent densities of green and baked anodes increase by over $0.02 \mathrm{~kg} / \mathrm{dm}^{3}$ and 0.015 $\mathrm{kg} / \mathrm{dm}^{3}$, respectively [3].

At the beginning of the vibro-compaction process, the mould is attached to the vibrating table and all the vibrations are propagated under the follower weight which is lowered freely on the paste. When the desired degree of densification is reached with a required vibrating time, the mould is separated from the vibratory assembly and the finished block of anode is pushed laterally outside the mould.

\section{Vibrating table}

The vibrating table is one of the most important vibro-compactor components. The vibration isolator for the table has changed in the course of time. During the initial stages of the development of the vibrating table, the vibration isolator was made of helical steel. Later, it was replaced by a solid rubber block. Now, the compressed air inflatable rubber is used as a vibration isolator [4] [5]. The vibration of the vibrating table is largely influenced by the calibration of the angle of the eccentric counterweights. Figure 2 shows the different vibration isolators. 


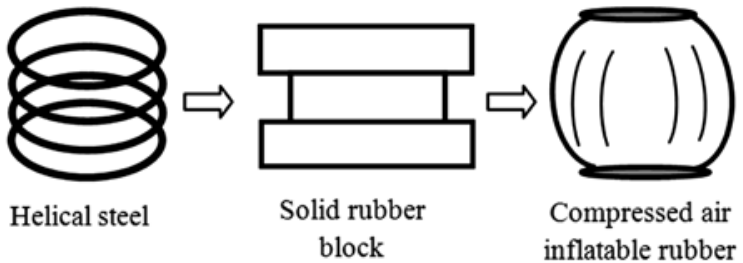

Figure 2: Evolution of different vibration isolators' with time.

\section{Eccentric counterweights}

The vibro-compactor also consists of four eccentric counterweights located on the two shafts. Their balances can be changed by changing the angles of unbalance and used to increase or decrease the magnitude of the vibrating load. The two shafts must be in the same orientation to ensure that all the forces act in the vertical direction and the vibration is balanced. The figure 3 shows these eccentric counterweights.

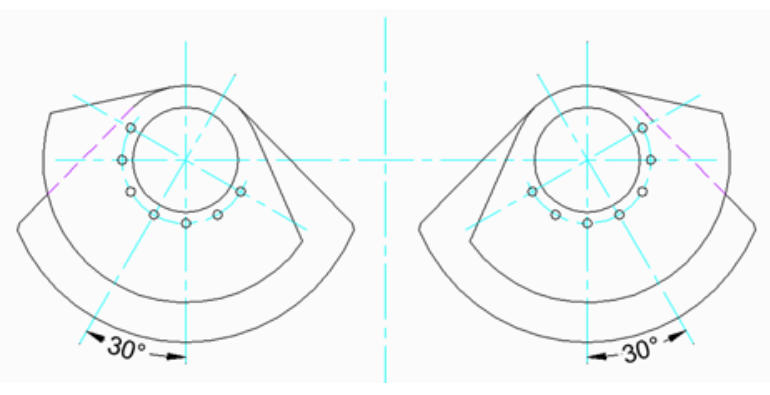

Figure 3: Eccentric counterweights drawing.

There must be angles of unbalance at each corner of the vibrating table, sufficient to have reasonably a uniform vibration of the anode paste. A non-uniform distribution of angles of unbalance may cause the formation of non-homogeneous anodes.

\section{1-D dynamic model}

A vibratory machine, which is mounted on elastic supports always, has a characteristic resonance frequency which depends on the weight of the vibratory machine and the stiffness of the supports. If the machine with a rigid support weighs less, the resonance frequency will be high. Heavy machinery on highly elastic supports will have a low resonance frequency [6]. The second case is the condition used in this study.

Figure 4 shows a 1-D dynamic model of a vibro-compactor developed in order to study the motion of the vibro-compactor and the vibration parameters. The vibro-compactor is modeled as a rigid mass $M_{T}$ suspended on springs $k_{T}$ and dampers $b_{T}$ and subjected to harmonic external excitation $f(t)$.

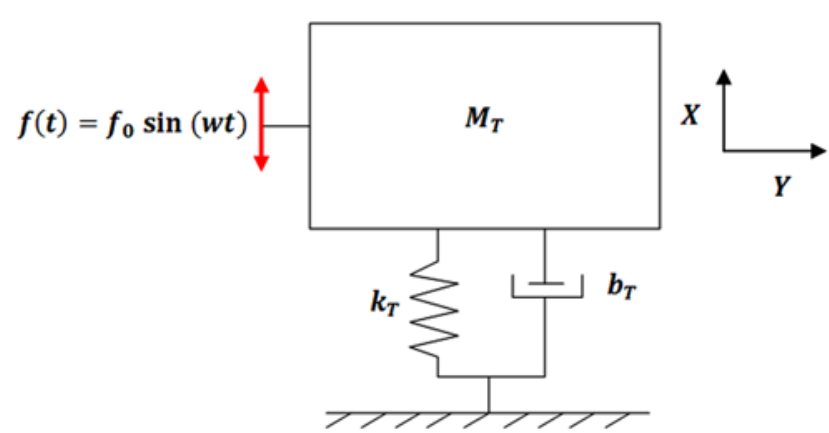

Figure 4: 1-D dynamic model of a vibro-compactor.

The total mass of a vibro-compactor can be represented by the equation (1). It represents the sum of the masses of vibrating table, anode, mould and total weight of the cover. Equations (2) and (3) present the external excitation of a vibratory compactor. The external force can be represented by a sinusoidal force acting on the whole system.

$$
M_{T}=m_{1}+m_{2}
$$

where;

$M_{T}$ : Total mass

$m_{1}$ : Vibrating table, mould and anodes masses equal to $3650 \mathrm{~kg}$.

$m_{2}$ : Cover weigh mass equal to $6270 \mathrm{~kg}$.

$$
f(t)=f_{0} \sin (w t)
$$

and

with:

$$
f_{0}=k_{T} \cdot x
$$

$f(t)$ : External excitation force $(\mathrm{N})$.

$f_{0}$ : Force amplitude $(\mathrm{N})$.

$w:$ Frequency (RPM).

$t$ : Vibrating time (s).

$k_{T}$ : Total rubber support rigidity $(\mathrm{N} / \mathrm{m})$.

$b_{T}$ : Total rubber support damping $(\mathrm{N} \mathrm{s} / \mathrm{m})$.

The numerical values of the parameters of the dynamic model are shown in a Table I. These values were obtained based on data from the article of $\mathrm{M}$. Beilstein et al [1].

Table I: Dynamic model parameters.

\begin{tabular}{|cc|}
\hline Parameters & Values \\
\hline Total mass & $9920 \mathrm{~kg}$ \\
Rubber support rigidity & $18.2 * 10^{6} \mathrm{~N} / \mathrm{m}$ \\
Rubber support damping & $5000 \mathrm{~N} \mathrm{~s} / \mathrm{m}$ \\
Amplitude & $5 \mathrm{~mm}$ \\
Vibrating time & $45 \mathrm{~s}$ \\
Frequency & $1300 \mathrm{RPM}$ \\
\hline
\end{tabular}




\section{Analytical model}

The equation of motion is solved using the following two methods for the model shown in figure 4. First, an analytical approach, which corresponds to a direct solution of the motion equation, is used. The second approach is based on the use of the Simulink interface of Matlab software. In this section, the analytical model is presented.

The equation of motion can be written as follows:

$$
M_{T} \cdot \ddot{x}+b_{T} \cdot \dot{x}+k_{T} \cdot x=f(t)
$$

This is a non-homogeneous linear differential equation of second order with constant coefficients. The general solution of this equation can be obtained by the sum of the complementary solution of the homogeneous equation and the particular solution of the equation with the non-homogeneous term (forced response).

If:

$M_{T} \cdot \ddot{x}$ : Inertia force.

$b_{T} \cdot \dot{x}$ : Viscous resistance force.

$k_{T} \cdot x$ : Elastic force.

Then

$$
\ddot{x}+2 \xi w_{n} \cdot \dot{x}+w_{n}^{2} \cdot x=\frac{f(t)}{M_{T}}
$$

All the four terms obtained have the physical dimension of acceleration. The general solution of the system under damped condition is represented below:

$$
x=A e^{-\xi w_{n} t} \cos \left(w_{d}+\varphi\right)+X \cos (w t+\varphi)
$$

\section{Analytical results}

The results obtained by solving the equation (4) are represented in the figure 5. The maximum displacement was equal to $0.9 * 10^{-3} \mathrm{~m}$ for an excitation amplitude of $5^{*} 10^{-3} \mathrm{~m}$.

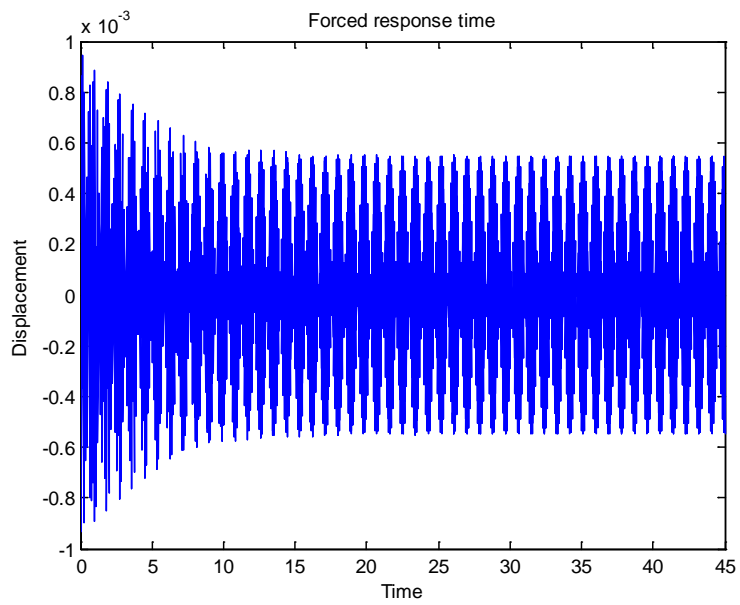

Figure 5: Total displacement versus time [ $m$ versus $s]$.

\section{Numerical model}

It is necessary to use numerical computation techniques to obtain an approximate solution of the equations of motion. In this section a second approach is presented based on the use of Simulink interface. This technique requires the construction of a schematic block representing the equations of motion. The figure 6 illustrates the dynamic model used in Simulink. The driving force of the system was the input as shown in figure 7 on Simulink interface.

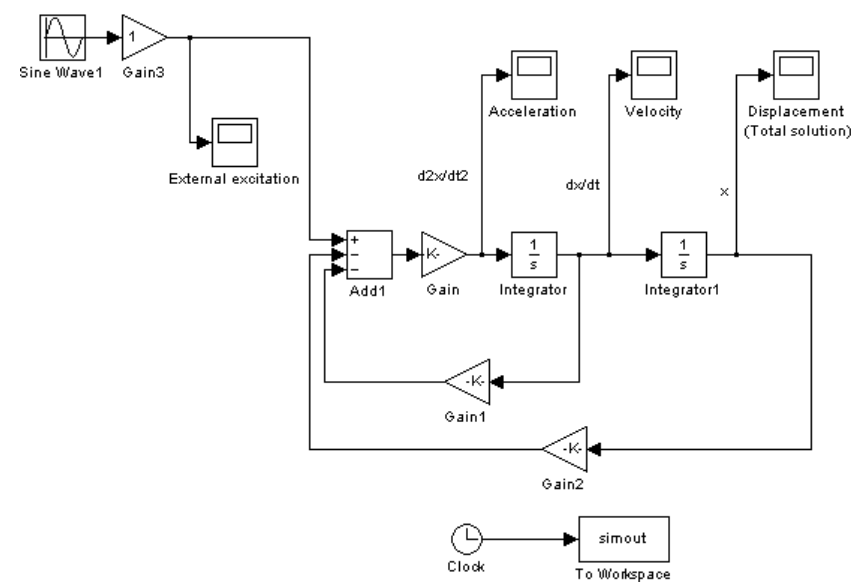

Figure 6: 1-D Simulink model of a vibro-compactor.

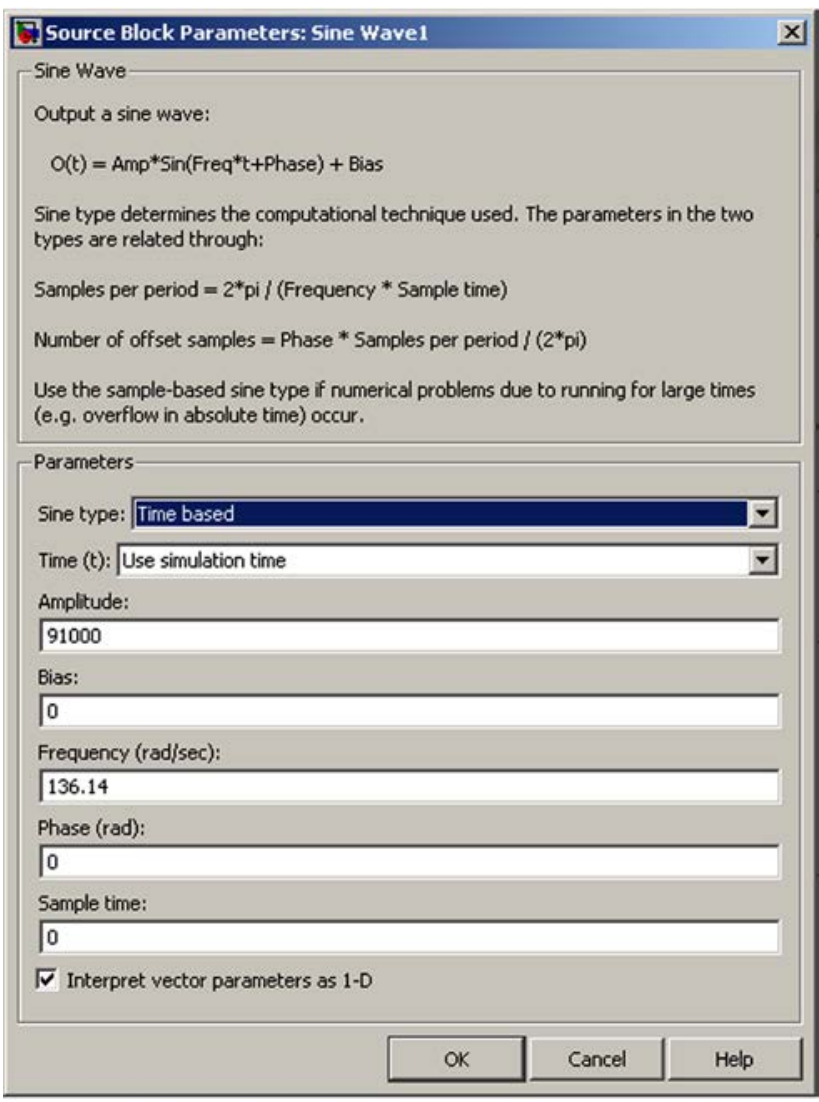

Figure 7: Input sinusoidal function with Simulink interface. 


\section{Numerical results}

The results obtained for the displacement, velocity and acceleration of the 1-D system are shown in figures 8, 9 and 10 respectively.

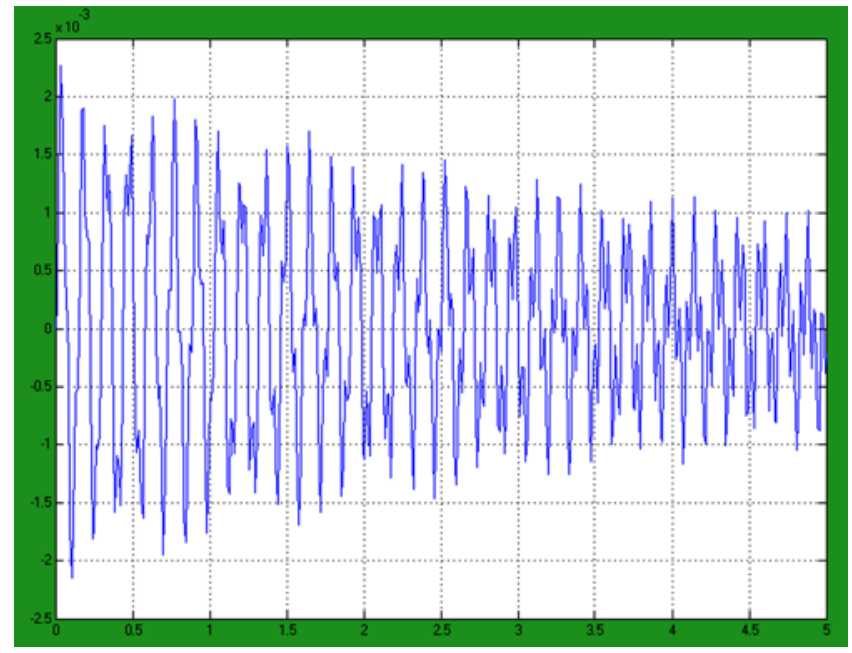

Figure 8: Total displacement versus time [ $m$ versus $s]$.

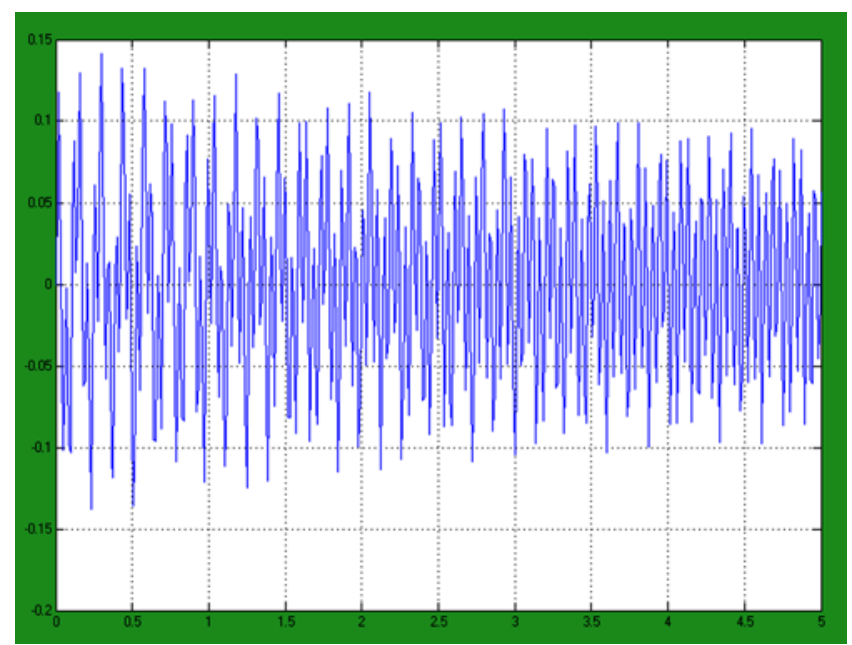

Figure 9: Velocity versus time $[\mathrm{m} / \mathrm{s}$ versus $\mathrm{s}]$.

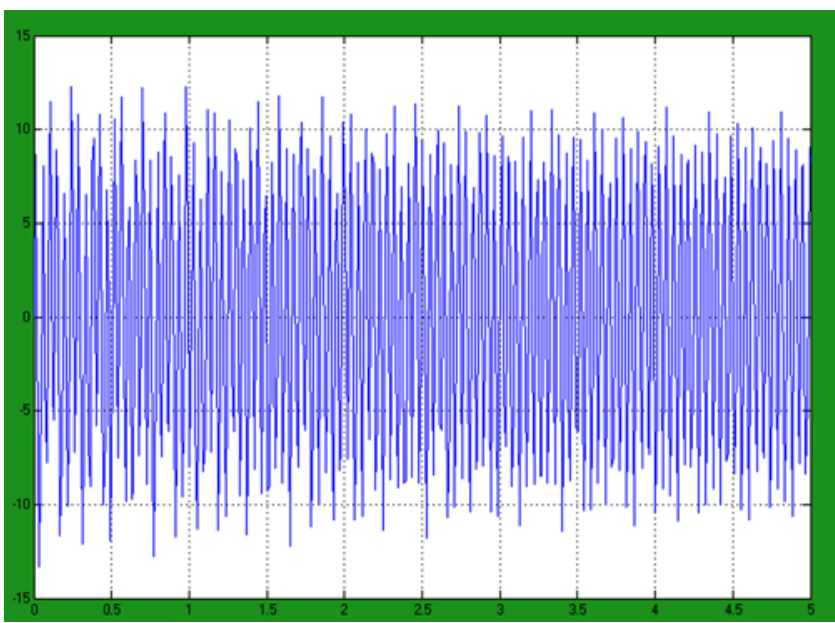

Figure 10: Acceleration versus time $\left[\mathrm{m} / \mathrm{s}^{2}\right.$ versus $\left.\mathrm{s}\right]$.

The maximum displacement, velocity and acceleration obtained in this case are equal to $2.3 * 10^{-3} \mathrm{~m}, 0.14 \mathrm{~m} / \mathrm{s}$ and $12 \mathrm{~m} / \mathrm{s}^{2}$, respectively. With this developed numerical model, it is possible to vary different parameters of vibration. As an example, table II presents the corresponding amplitude responses with variation of the excitation frequency. The values of excitation amplitude responses for frequencies varying from 10 to $220 \mathrm{rad} / \mathrm{s}$ [95.5 to 2100 RPM] are presented in the table II.

Table II: Amplitude response with respect to different frequencies of vibration.

\begin{tabular}{|c|c|}
\hline Frequency (rad/s) & Amplitude (m) \\
\hline 10 & 0,0059 \\
\hline 30 & 0,0016 \\
\hline 40 & 0.064 \\
\hline 42 & 0,17 \\
\hline 42.8 & 0,3 \\
\hline 44 & 0.13 \\
\hline 50 & 0.028 \\
\hline 70 & 0.0064 \\
\hline 100 & 0.0034 \\
\hline 140 & 0.0024 \\
\hline 180 & 0,0014 \\
\hline 220 & 0.0012 \\
\hline
\end{tabular}

The amplitude variation curve versus the frequency of vibrocompactor 1-D system based on the values presented in the table II is shown in figure 11 . It may be noted that the system resonance occurred at around 409 RPM (42.8 rad/s) with an amplitude of 0.3 $m$. This was in good agreement with what happens in reality. 
Amplitude variation according to the excitation frequency

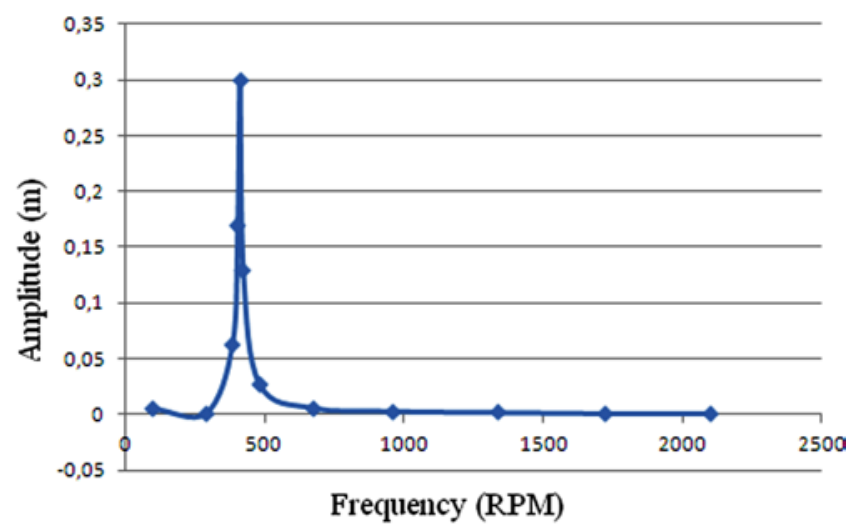

Figure 11: Amplitude versus frequency.

The natural frequency of a vibrating machine generally varies between 200 and 800 RPM. This value is very decisive for the vibrating machine because if any of the excitation frequency coincides with the natural frequency of the vibro-compactor, then resonance phenomena will occur which may leads to excessive deflection, high stress concentration and machine damage.

\section{Analysis of results}

Both the methods used for the solution of the equations of the motion gave similar results with a certain degree of error. The cause of this error was that the both methods were approximate. The analytical method was based on the programming of the homogeneous and particular solution of the general equation of motion and, on the other hand, the numerical method was like a black box. The numerical method was more powerful because it allowed the resolution of non-linear equations which can easily handle the case of two-dimensional systems with variable input parameters. The acceleration obtained by the numerical model was $1.2 \mathrm{G}$; which was comparable to that obtained for an experimental measurement of the vibration of the vibrocompactors in the industry.

\section{Conclusions}

The vibro-compaction is a very complex process that significantly affects the quality of anodes produced. So far, there are not many studies published dealing with this subject. The time of vibration, the vibration frequency and the vibration force; are the important parameters influencing the quality of the anodes in terms of the mechanical properties.

Therefore a dynamic study and a vibration measurement of a vibro-compactor can help understanding this system in a better way and thus help to detect the presence of faults before it is too late. The application of this approach will enrich research, especially on the part of vibro-compaction which is a critical area in the field of anode production.

\section{Acknowledgements}

The technical and financial support of Aluminerie Alouette Inc. as well as the financial support of Développement économique SeptÎles, Natural Science and Engineering Research Council (NSERC) of Canada, University of Quebec at Chicoutimi, and Foundation of University of Quebec at Chicoutimi are greatly appreciated.

\section{References}

1. M. Beilsein and M. Spangehl, "Vibrocompacting machines for the moulding of green anodes-process development from the equipment supplier's point of view”, Light Metals, Materials and Properties, (1998), 745-752

2. Werner K. Fischer and Markus W. Meier, “Advances in Anode Forming”, Light Metals, Anode Plant: Retrofitting \& Operation, (1999), 541-546

3. kristine Luise Hulse, “Anode Manufacture: Raw Materials, Formulation and Processing Parameters”, (2000)

4. Outokumpu, (2004), "Alumina and aluminium technologies", Finland.

5. Benoît Coste and Claude Vanvoren, "Suspension pneumatique des vibrotasseuses utilisées en particulier pour la production de blocs carbonés”, (1988), EP0251942 A1

6. Marc Thomas and Frédéric Lavaille, (2007), "Simulation des vibrations mécaniques par Matlab, Simulink et Ansys”, presses de l'université du Québec. 